\title{
Using this Book
}

The need for translation from English into Arabic and vice versa has grown substantially since $9 / 11$ and the war on Iraq in 2003. Such a need has increased demands for translation services from and into these two languages. Unfortunately, the educational market has suffered from a lack of textbooks that address translation from a practical point of view, taking into consideration the changing nature of the translation market on social, economic and political levels. Translation is a highly demanding process that involves much more than utilising and converting words and phrases from one language into another, and translators and learners need a practical book that addresses the skills and sub-skills of translation: this book is designed to address some of these needs.

This book introduces learners to translation from English into Arabic through a wide range of practical exercises. With a variety of texts and multiple drills, it is hoped that learners will be able to develop and refine their translation skills. The book introduces learners to drills related to the translation of texts within basic genres, and covering translation sub-skills. It aims to present an efficient and practical approach to learning the skills of translating different text types from English into Arabic. Whilst most of the published translation books tend to focus on the theoretical aspects of translation from the source text (ST) to the target text (TT), this book follows a practice-based approach in order to assist learners in utilising the concepts and theoretical frameworks they have learned. Some theoretical aspects of translation are introduced in the first four modules, but readers are urged to consult other books that elaborate at length on these theoretical aspects.

As well as offering advanced materials for translation from English into Arabic, the book also includes a wide range of drills pinpointing the differences between the source language (SL) and the target language (TL) so that learners and translators can refresh their knowledge of some aspects of the TL.

Not only will the book be useful to those learners who wish to familiarise themselves with the different typology of Arabic and English texts, it will also equip them with some necessary translation skills. Furthermore, the book introduces students to general translation skills by focusing on specific technical texts that require certain 'detective' skills, which students learn through the practical drills offered on each text. These drills are designed to help learners progress through the word level, sentence level and discourse level. Since context is at the heart of translation, students are introduced to a variety of drills that allow them to translate different elements of discourse in their appropriate context.

It is hoped that the practical drills will enhance learners' skills in selecting appropriate equivalence to the ST, especially in the translation of technical texts. In addition to mastering knowledge of both languages, translators need to have a good command 
of specific registers, some of which will be acquired through specialised dictionaries, encyclopaedias and technical literature in both languages. In order to facilitate learners' comprehension and translation of texts, a glossary of some technical words and phrases is provided at the end of each text. On completing this book, learners should have acquired technical vocabulary at an advanced level, further enhancing their ability to translate from English into Arabic.

All in all, this book is intended to improve and strengthen learners' translation skills, and refine and expand their knowledge of different genres of texts. The main objectives can be summarised as follows:

1. introducing learners to the main features of different genres of texts

2. identifying the linguistic and cultural features of different text types

3. equipping learners with the necessary skills to deal with the translation of different genres of texts from English into Arabic, through practical translation drills

4. enhancing awareness of pragmatic, semantic and sociolinguistic aspects during the translation process.

\section{Key to Symbols}

Glossary

Translation 